\title{
Difficulties in Defining Social-Emotional Intelligence, Com- petences and Skills - a Theoretical Analysis and Structural Suggestion
}

\author{
Moana Monnier \\ University of Neuchâtel \\ Institute of Work and Organizational Psychology \\ Rue Emile-Argand 11, 2000, Neuchâtel, Switzerland \\ E-mail: moana.monnier@unine.ch \\ Federal Institute for Vocational Education and Training (BIBB) \\ Department of Competence Development \\ Robert-Schuman-Platz 3, 51375, Bonn, Germany \\ E-mail: monnier@bibb.de
}

\begin{abstract}
Demands related to the frequency of and time required for interactional tasks in everyday occupational routines are continuously growing. When it comes to qualifying a person's ability to interact with others, two prototypical concepts are often used: social competences and emotional intelligence. In connection to discussions about curriculum standards in Germany, these are viewed as important attributes that should be taught, supported and if possible assessed in educational pathways toward an occupation. However, in looking for a generally approved and widely used definition, many problems arise on the inter-conceptual and intra-conceptual level, triggering implementation difficulties in educational curricula. This article highlights these difficulties by selecting five well-established key theories and comparing their communalities and differences. Analyzing definitions of intelligence, competences and skills, taking an action regulation perspective and highlighting the interdependence of social and emotional aspects, a structural system to facilitate the transfer into the educational context is proposed.
\end{abstract}

Keywords: Social competence, emotional intelligence, social skills, educational curricula, action regulation

\section{Bibliographical notes:}

Moana Monnier is a research associate at the University of Neuchâtel, Switzerland and works as a scientific collaborator at the Federal Institute of Vocational Education and Training (BIBB) in Bonn, Germany. Her research interests are interactions and their related competences and intelligence dimensions with a focus on educational and work situations. 


\section{Introduction}

Demands in modern occupations are continuously growing. In parallel, there is also increasing recognition of the significance of the ability to facilitate positive social interaction as a component of occupational professionalism. This demands adaptation of classical educational curricula and causes interdisciplinary debates regarding the teaching and assessing of individual skills, competences and intelligence in the present and future. In particular, these debates introduce terms like " $21^{\text {st }}$ century skills" (Ananiadou and Claro, 2009), the underlying purpose of which is to enhance success in "work, citizenship, and self-actualization" (Dede, 2007, p. 4) and therefore to foster capabilities adapted to the continuously growing demands emerging as a result of globalization and rapid development of information and communication technologies. The core competencies presented by the Organization for Economic Cooperation and Development (OECD) are one example. They encompass a large portfolio of attributes and characteristics including both "interpersonal core competencies" as well as "delivery-related" and "strategic" ones (OECD, 2013, p. 4). When it comes to qualifying a person's ability to interact with others, prototypical concepts such as social competence or emotional intelligence are often used. These are seen as important contributors to successful interactions, along with such factors as emotional competence, social skills and social intelligence. Nevertheless, the theoretical foundation has incongruities and overlaps in the definitions and meanings of these concepts. And these significantly impede transfer to educational curricula.

This paper presents a theoretical investigation of the types of intelligence, competences and skills necessary to cope with the growing scope of social interactions at work and everyday life. Furthermore, it pinpoints the causes of difficulties in application and transfer to syllabi and assessments. Finally, a workable solution for facilitating implementation through a systematic structure is proposed.

\subsection{Inter-conceptual confusion in defining social-emotional intelligence, com- petences and skills}

Interdisciplinary research activity on the subject of social interactions and the competences they require has increased enormously in recent years (Kanning, 2002). In parallel with this development, one can observe consistent confusion arising from the use of concepts such as social competence, social intelligence, social skills, soft skills, emotional intelligence, etc. In a study for the National Educational Panel Study (NEPS) in Germany, Bayer, Ditton and Wohlkinger (2012) note that there is no generally accepted definition and delimitation of the concepts of social skills, interactional skills, assertiveness, self-esteem, social or interpersonal competence in the many published studies (Döpfner et al., 1981; Rose-Krasnor, 1997; Arnold et al., 2012). These concepts are sometimes used synonymously, sometimes as components of one other and sometimes as entirely separate properties. Beelmann et al. (1994), for example, regard social competences as the "more general term" (p. 1) for social skills. Yet the same two concepts are viewed as components of one another in Baron and Markman's (2003) definition of social competences as the "ability to interact effectively with others as based on discrete social skills" (p. 1). And finally, Warnes et al. (2005) postulate them as two different concepts, with social skills seen as behavior that facilitates effective interaction and social competences as a person's interactional quality as perceived by others. Another point of inter-conceptual confusion is that theories considered to be very different from one another actually share 
many common components. Mayer and Salovey (1997), for example, define emotional intelligence as "the ability to perceive emotion, use emotion to facilitate thought, understand emotions, and manage emotion" (p. 3). This is not unlike Kanning (2002), who regards social competence as containing the behavioral control of emotions, meaning the ability to control one's feelings both internally and externally.

These incongruities and overlaps necessitate a great deal of effort to find a shared vocabulary. They are a sign that these constructs derive from a common theoretical basis of underlying skill, competence and intelligence dimensions that need to be precisely defined. A "concept clean-up" (Organ, 1997) is needed.

\subsection{Intra-conceptual confusion, as exemplified by social competence defini- tions}

The confusion caused by unclear attribution of the underlying skill, competence or intelligence dimensions described above continues at the intra-conceptual level. The example of social competences highlights this confusion. There are still many disagreements on the definition of social competences (Kanning, 2005). The multitude of different attempted definitions and systematizations is largely based on plausibility assumptions, and these are usually not empirically derived (Kanning, 2003). Accordingly, the term can be used as an all-embracing construct that permits wideranging interpretations, and can be concretized in diverse and to some extent arbitrary ways (Euler and Bauer-Klebl, 2008). On top of that, Seyfried (1995) points out the difficulties in measuring social competences because of the unclear nature of the theoretical construct. The necessity of identifying the obstacles that lead to these heterogeneous definitions of social competence is obvious. Firstly, it is apparent that as a result of the endless variety of social situations and social partners, a specific behavior can be good in one situation yet lead to escalation in another. This contradictory normative foundation necessitates highly abstract definitions that are not oriented to application. Secondly, there is still no explicit internationally accepted and valid definition of the meaning of competence and consequently of competence assessment. In its background paper on DeSeCo (Definition and Selection of Competencies) (2001), the OECD summarizes Weinert's analyses (2001a) on the subject of competences by stating that there is "no single concept" (p.6) and describe his recommendations to competences as "a pragmatic approach in which competencies should be conceptualized as the necessary prerequisites for meeting complex demands" (p.6). These prerequisites are trainable for specific requirements (Hartig and Klieme, 2006), giving them a concrete nature in comparison to intelligence concepts that are valid "for a large variety of situations" (Klieme et al., 2007, p.6). However, the performance aspect of competence remains unclear. According to Weinert, "those prerequisites that can in principle be fully automatized can also be characterized as skills. The boundary between skill and competencies is fuzzy" (2001a, p.62). This causes considerable difficulties, not only in defining a specific competence or skill dimension, but also in the educational implementation demanding objective predications of people's competence level through impartial assessments of their performance.

In summary, it is obvious that reducing the number of contradictory definitions of social competence and similar concepts will require more than just a clearly defined framework of social situations in which these definitions are valid (Schuler and Barthelme, 1995). In order to obtain an objective assessment, it is also important to consider skills indicating a person's "competence" level. From a VET perspective, 
a job-specific approach defining clear situational demands with regard to the professional role and associated behaviors for the performance aspect could serve as a definition framework. A new field of research covering the transmission and thus concretization of generalized personal and social competence models into job-specific personal and social competence models is therefore emerging. Recent examples include the study on bankers by Tschöpe (2012) and on medical assistants by Dietzen et al. (2012).

\section{Theoretical background}

Although many authors are aware of the problems mentioned above (for example there is critique of the one-dimensionality of social intelligence, demanding that it be described as a composition of multiple capabilities (Boyatzis et al., 2004; Bar-On, 1992; Goleman, 1998; Saarni, 1990), there have been no proposals for structuring the entire field of research. Instead, there have been individual adaptations that only add to the confusion. In this section, we present five theories, their definitions and exemplary measurements. We compare them and identify the source of possible ambiguities.

\subsection{Social competences}

\subsubsection{Theoretical approaches to social competence}

As described above, there are still many disagreements on the definition of social competences (Kanning, 2005). Nevertheless, some uncontested generalized models do exist. Arnold et al. (2012), for example, define social competences as attributes of people who are able to interact with others in such a way that their behavior has a maximum positive and minimum negative outcome for the interactional partners. However, from an educational perspective, the fundamental nature of this definition is highly problematic since there is no application-oriented translation. The consequences are numerous "sub-definitions" containing concrete capacities needed in specific situations. These definitions and systematizations are largely based on plausibility assumptions (Kanning, 2003) and can be concretized in diverse and to some extent arbitrary ways (Euler and Bauer-Klebl, 2008). The all- embracing and integrative nature of the concept is thus lost (Waters and Sroufe, 1983). This gives rise to the essential question: If a model of social competences must be highly abstract in order to be generally accepted, what needs to be fostered and assessed in the concrete educational context? Two solutions can be found in the literature.

On the one hand, all possible sub-dimensions of social competences can be gathered and groups of associated components can be formed. One example of this is Kanning's development of the first German inventory for measuring general social competences (Inventar Sozialer Kompetenzen, ISK, 2009). He statistically identifies four factors that summarize general social competences: 1. Social-openness 2. Being offensive 3. Self-regulation 4. Reflexivity. Unfortunately, the ISK is based on selfevaluation, therefore compromising its objectivity in educational contexts.

On the other hand, for the VET context, one can look at complete representations of (future) occupational contents, boundary conditions, normal duties and activities (also known as the domain model (Winther, 2010)). Necessary social competences for meeting these demands can be directly deduced. There are only a handful of examples of this approach, such as the study by Tschöpe (2012) on bankers or by Dietzen et al. (2012) on medical assistants. Both of them developed a job-specific assessment for social competences at the end of the apprenticeship in Germany. The 
latter found three competence dimensions defining the concept, namely emotion regulation, perspective coordination and perspective-taking, and communication (encompassing listening, communication strategies and comprehensible language). Both approaches are promising and could conceivably be combined. The ideal way to do so would be to create a generally valid "catalogue" containing all possible attributes of social competence. From this catalog, one could then select the necessary components for a specific environment. This would pave the way for a general definition that permitted contradictory competences in different environments or occupations without the entire concept of social competences being called into question. A possible structure for such a reference catalogue is presented below.

\subsubsection{Existing measurements of social competence}

There are three different approaches for measuring social competences (Arnold et al., 2012). They differ considerably in their implementation possibilities. Firstly, there are self-reports based on questionnaires or interviews. They compose the majority of the existing assessments. Secondly, there are reports on a person's qualities by peers or experts, such as $360^{\circ}$ (multi-source) assessments. These represent a more complex and less economical method of collecting individual information. And finally there is behavioral monitoring. If evaluated by strictly objective criteria, it is the most significant method of assessing social competences. Its realization is very complex, however. The new ability-based tests alluded to earlier (Tschöpe, 2012; Dietzen et al., 2012) are not described here due to their specific nature. As examples, we present three validated assessments of general social competences and their underlying scales.

Inventar Sozialer Kompetenzen (ISK, Inventory of Social Competences) (Kanning, 2009):

- Questionnaire based on self-reports

- First application 2009, reliability coefficients between .69 and .90

- 17 scales grouped into four primary scales:

- Social orientation (pro-sociality, perspective-taking, pluralism of values, willingness to compromise, listening)

- Being offensive (assertiveness, conflict readiness, extraversion, decisiveness)

- Self-regulation (self-control, emotional stability, flexibility in acting and internality)

- Reflexivity (self-expression, direct self-attention, indirect self-attention, person perception) 
Social Competence Scale (SCS) as in (Gouley et al., 2008):

- Questionnaire based on self-reports or reports by parents or peers

- First application 1995, reliability coefficients between .84 and .89

- Only for children

- Two scales:

- Emotion regulation

- Pro-social behavior or communication skills

Social Competence and Behavior Evaluation Scale (SCBE-30) as in (LaFreniere et al., 1996 and 2002):

- Questionnaire based on self-reports or reports by teachers

- Only for children

- First application 1995, reliability coefficients between .78 and .92

- Three scales:

- Social competence (being joyful, confident, tolerant, socially integrated, calm, pro-social, cooperative and autonomous)

- Trouble/aggression (demonstrating behavior of this nature)

- Fear/withdrawal (demonstrating behavior of this nature)

These three assessment methods exemplify the content of social competence assessment. No standardized measures for behavioral monitoring have been found. Yet such standardization would be important considering the necessity to evaluate social competence levels in VET through practical exams and role playing.

\subsection{Emotional intelligence}

\subsubsection{Theoretical approaches to emotional intelligence}

In comparison to social competences, intra-conceptual confusion in regard to the definition of emotional intelligence (EI) seems negligible at first. EI also appears to be less abstract, which would permit concrete stimulation of EI components in the educational context. However, in looking at significant definitions, one finds overlaps or at least dependencies on other concepts that contribute to the inter-conceptual confusion. Bar-On (2006), for example, shows that social and emotional intelligence concepts have much in common and argues in favor of a joint concept of emotionalsocial intelligence. To make things more complicated, even though Mayer et al. (1999) demonstrate that EI complies with traditional standards of intelligence, there is no explicit differentiation between the concepts of emotional intelligence and emotional competence. Instead, they are viewed as nested concepts or used to some extent as interchangeable. There are EI definitions composed of descriptions of human disposition, illustrations of personality with links to theories of action (Goleman, 1995) or based on competence (Boyatzis et al., 2000) or ability (Conte, 2005). Consequently, many EI assessments (self-report, see 2.1.2 for differentiation) seem to measure personality characteristics or indeed emotional competence (Conte, 2005) instead of intelligence (Mayer et al., 1999). Bar-On (2006) illustrates this phenomenon by describing the EI competences assessed by each scale of the Emotional Quotient Inventory (EQ-i) (Bar-On, 1997a and 1997b) described below.

On the intra-conceptual level, the definitions nevertheless seem to be congruent. The definition of EI as being "a form of social intelligence that involves the ability 
to monitor one's own and others' feelings and emotions, to discriminate among them, and to use this information to guide one's thinking and action" (Salovey and Mayer, 1990, p. 5) forms the basis for the Mayer-Salovey-Caruso Emotional Intelligence Test (MSCEIT) (2002b), an important EI assessment tool. According to Boyatzis et al. (2000), "emotional intelligence is observed when a person demonstrates the competencies that constitute self-awareness, self-management, social awareness, and social skills at appropriate times and ways in sufficient frequency to be effective in the situation" (p. 3). This led to the construction of the above-mentioned Bar-On Emotional Quotient Inventory (EQ-i) (1997a, 1997b). When these two are compared, many similarities become apparent: Self-awareness can be seen as monitoring one's own feelings, self-management as using the information to guide one's thoughts (and action), social awareness as monitoring others' feelings and emotions and finally social skills as using the information to guide one's (thoughts) and action. Unfortunately, research shows that, empirically speaking, the different measures don't converge in a common construct (Conte, 2005).

\subsubsection{Existing measurements of emotional intelligence}

Three generally accepted and validated EI assessments are presented below. Due to the structure of this paper, the Emotional Competence Inventory (ECI) (Boyatzis et al., 2004) is described in the chapter on emotional competence even though it is used in EI assessments.

The Emotional Quotient Inventory (EQ-i) (Bar-On, 1997a and 1997b):

- Questionnaire based on self-reports

- First application 1996, reliability coefficients between .69 and .86

- Five composite scales:

- Intrapersonal (self-regard, emotional self-awareness, assertiveness, independence, self-actualization)

- Interpersonal (empathy, social responsibility, interpersonal relationships)

- Stress management (stress tolerance, impulse control)

- Adaptability (reality testing, flexibility, problem-solving)

- General mood (optimism, happiness)

Mayer-Salovey-Caruso Emotional Intelligence Test (MSCEIT) (Mayer et al., 2002a and 2002b):

- Ability test

- Evaluated by expert or consensus scoring

- First application 2000, reliability coefficients between .73 and .93

- Four composite scales:

- Perception of emotion

- Integration and assimilation of emotion

- Knowledge about emotions

- Management of emotions 
Emotional Intelligence Scale (EIS) (Schutte et al., 1998):

- Questionnaire based on self-reports

- 33 items, very short

- Conceptual foundations based on Salovey and Mayer (1990)

- First application 1998, reliability $=.90$

- Three composite scales:

- Appraisal and expression of emotion

- Regulation of emotion

- Utilization of emotions in solving problems

\subsection{Emotional competences}

\subsubsection{Theoretical approaches to emotional competence}

Emotional competences have been overshadowed by social competences and emotional intelligence, and accordingly less research has been conducted on them (Weis, 2008). Similar to other concepts, an all-embracing definition is lacking but a general consensus as to the nature of emotional competence is recognizable. Even though emotional competences stand for themselves, independent definitions clearly detached from emotional intelligence are difficult to find. Goleman (1998), for example, describes emotional competence as the "learned capability based on emotional intelligence that results in outstanding performance (at work)" (p. 24), meaning that emotional competence is the application of emotional intelligence in to something applied. Scherer (2007) even goes so far as to criticize use of the term "intelligence" in "emotional intelligence," suggesting instead that model of emotional intelligence be converted into a model of emotional competence based on his Componential Emotion Theory (Scherer, 2001). He differentiates between perceiving and producing competences. Perception competence encompasses accurate perception, recognition and interpretation of signals, while production competence is broken down into three sub-competences:

1. Appraisal competence as "appropriate emotion elicitation and differentiation", 2. Regulation competences as the ability to "correct inappropriate emotional responses produced by unrealistic appraisals" and 3. Communication competences being the "production of emotional expressions optimally suited to a purpose and the accurate signal perception and receiving ability" (Weis, 2008, p. 74; Scherer 2007).

In addition to the natural commonalities with emotional intelligence, we observe that the capability of regulating one's emotional response also appears in the definition of social competence.

A new aspect, namely the dimension of time, is brought in by Lerner (2007), who defines emotional competence as "the ability to identify and manage one's emotions. This includes knowing how to nourish your emotional state, take turns, delay gratification, and cope with failure and loss" (p. 51). Few long-term strategies are found in existing assessments. Lerner adds "It also involves knowing how to control impulses, use good judgment and adapt emotions in response to others' emotions and reactions" and thus converges towards the definitions of social competence and emotional intelligence outlined above. In summary, one can see that emotional competence and its connection to emotional intelligence and sometimes even to social competence contribute to the inter-conceptual confusion. They nevertheless appear to represent a pathway to the behavioral output arising from emotional intelligence. 


\subsubsection{Existing measurements of emotional competence}

Two generally accepted and validated emotional competence assessments are presented below. Despite its name, the Emotional Competence Inventory (ECI) (Boyatzis et al., 2004) is often used in emotional intelligence assessments. The clusters in its underlying competence dimensions are very detailed and based on Goleman's definition of emotional intelligence from 1998.

Emotional Competence Inventory (ECI) (Boyatzis et al., 2004):

- Questionnaire based on self-reports or reports by others $\left(360^{\circ}\right)$

- First application 1999, reliability coefficients between .68 and .87

- Five scales / clusters:

- Self-awareness cluster (emotional awareness, accurate self-assessment and self-confidence)

- Self-regulation cluster (self-control, trustworthiness, conscientiousness, adaptability and innovation)

- Motivation cluster (achievement drive, commitment, initiative and optimism)

- Empathy cluster (understanding others, developing others, service orientation, leveraging diversity and political awareness)

- Social skills cluster (influence, communication, conflict management, leadership, change catalyst, building bonds, collaboration and cooperation and team capabilities.)

Emotionaler-Kompetenz-Fragebogen (EKF, Emotional Competence Questionnaire) (Rindermann, 2009):

- Questionnaire based on self-reports or reports by others

- First application 2009, reliability coefficients between .89 and .93

- Four scales:

- Recognizing one's own emotion (perceiving and understanding proper emotions)

- Recognizing others' emotions (being able to perceive and understand others' emotion by their behavior, their spoken communication, their facial expression and their gestures depending on the situation)

- Regulation and control of one's own emotions

- Emotional expressivity (being able and willing to express one's feelings)

\subsection{Social skills}

\subsubsection{Theoretical approaches to social skills}

In comparison to the other concepts, social skills clearly are behavior based. They contain firstly an understanding of and then secondly an adaption to social situations (Steedly et al., 2008). Yet independent definitions clearly detached from social competences are difficult to find, and the two terms are used interchangeably. According to a frequently cited definition from Walker (1983, p. 27), social skills are "a set of competencies that allow an individual to initiate and maintain positive social relationships, contribute to peer acceptance and to a satisfactory adjustment, and allow an individual to cope effectively with the larger social environment. "They form the 
base of many training activities and educational entities, such as in the context of Social Emotional Learning (SEL) through which people learn how to "to generate and coordinate flexible, adaptive responses to demands and to generate and capitalize on opportunities in the environment" (Waters and Sroufe, 1983, p. 80). In concrete terms, this means people learn how to recognize and manage emotions, showing and feeling concern toward others, initializing and maintaining positive relationships, making responsible decisions and acting ethically and constructively in difficult situations (Zins, et al., 2004). On the basis of these definitions, social skills, similar to the emotional competences, seem to represent the pathway to the behavioral output arising from social competences.

\subsubsection{Existing measurements of social skills}

Since social skills are evaluated primarily in school contexts, the measurements presented here have been adapted to school situations. The dimensionality is transferable nonetheless.

Social Skills Improvement System (SSIS) (Gresham and Elliott, 2008):

- Questionnaire based on self-reports or reports by parents or teachers

- First application 1990, reliability coefficients between .81 and .94 for scales as a whole

- Seven scales:

- Communication

- Cooperation

- Assertion

- Responsibility

- Empathy

- Engagement

- Self-control

Matson Evaluation of Social Skills with Youngsters (MESSY) (Matson et al., 1983):

- Questionnaire based on self-reports or reports by parents or teachers

- First application 1983, reliability coefficients between .85 and .89

- Five scales:

- Assertion

- Cooperation

- Self Control

- Empathy

- Responsibility

\subsection{Social intelligence}

\subsubsection{Theoretical approaches to social intelligence}

The original definition of social intelligence dates back to 1920 when it was described by Thorndike as "the ability to understand and manage men and women, boys and girls, to act wisely in human relations" (p. 228). Vernon (1933, p. 40) defines it more precisely as the "ability to get along with people in general, social technique or ease in society, knowledge of social matters, susceptibility to stimuli from 
other members of a group, as well as insight into the temporary moods or underlying personality traits of strangers." This encompasses a new dimension appears in addition to the direct detection of one's own and the interactional partner's condition. The concept of social intelligence is completed by knowledge of social norms common to the group with which one is affiliated as well as the social norms of the interactional partner's affiliation group. It appears to be an all-embracing construct containing all the others. Yet while the number of articles on emotional intelligence and social competences has exploded in recent years, especially since the official introduction of the term "emotional intelligence" in the 1980s (Weis, 2008), articles on social intelligence have taken a backseat.

\subsubsection{Existing measurements of social intelligence}

Assessments of social intelligence are difficult to find. Two will are presented below.

Tromso Social Intelligence Scale (TSIS) (Silvera et al., 2001):

- Questionnaire based on self-reports

- First application 2001, reliability $=.79$

- Three scales:

- Social information processing

- Social skills

- Social awareness

George Washington Social Intelligence Test (GWSIT) (Hunt et al., 1955):

- Ability test

- First application 1928

- Five scales:

- Judgment in social situations

- Recognition of the mental state of the speaker

- Memory for names and faces

- Observation of human behavior

- Sense of humor

\subsection{Conclusion}

Let us first turn our attention to measurement methods. These were selected by looking for assessments that claim to measure the described concepts. Since there is a pronounced prominence of theories on social competence and emotional intelligence, it was very difficult to find instruments that included all concepts. As a result, only local measurements have been found for some. It should also be noted that many of them are for children. Assessments of social-emotional intelligence, competence and skill assessments are lacking for adults. Ten of twelve methods are based on selfevaluations or evaluations by parents or peers, and are thus very difficult to use for ability based and objective measurements of intelligence, competence or skill levels, necessary for the educational context. Secondly, in light of this sample of prototypical definitions, the main source of the confusion alluded to in the introductory sections is quickly apparent, namely the lack of a clear demarcation between the concepts of intelligence, competence and skills. In some cases they are used as syno- 
nyms, while in others they are leveled from behavior to human disposition. In addition, some concepts are described in a generalized way while others tend to be application-driven and are referenced to a concrete environment. Clear action regulation levels (Hacker, 2003), structuring the contents by differentiating the extent to which conscious cognitive thought is required for the composing elements to be activated, are not described. Furthermore, many sub-components appear in several of these concepts, making demarcation of the concepts very fuzzy.

In summary, we can see that there are problems on many levels and we want to propose some solutions to them. Problems caused by the nature of the evaluation technique, for example, could be solved through use of situational judgment tests (Dietzen et al.) that enable measurement of a person's reaction to a stereotypical situation. The idea is that a person's acting in a certain situation is a good predictor of future performance in similar situations (Havighurst et al., 2003). The bias of selfevaluations could thus be avoided. Concerning the problems arising from the fuzzy demarcations of contents, we propose the fallowing: We summarized the presented theories to an all englobing field of social-emotional intelligence, competence and skills. For this, we looked at the differences and communalities of the presented theories and gathered all together. We then extracted six attributes covering all the contents found in the field. These attributes set the base for our proposed structural system for the field of social-emotional intelligence, competence and skills:

i. Attributes that enable awareness of one's inner state (emotions, cognitions, perception, consciousness, social rules)

ii. Attributes that enable control/management of one's inner state (emotions, cognitions, perception)

iii. Attributes that improve one's wellbeing

iv. Attributes that identify the state of others (emotions, people, groups, society)

v. Attributes that enable the control/management of others' inner state (emotions, cognitions, perception)

vi. Attributes that improve social interactions

These six attributes compose the field of social-emotional intelligence, competence and skills. They allow the collocation of sub-components helping the understanding and transition into application. They will serve as categories for the structure presented in the next chapter.

\section{Proposed clean-up}

A scientifically sound and unambiguous integration of the dimensions of socialemotional intelligence, competences and skills in educational and VET curricula, as exemplified by the OECD's Interpersonal Core Competencies, is highly desirable, even if only to facilitate the search for those components which should be taught, enhanced and stimulated. With this goal in mind, we identify a structure behind the theories outlined in the previous sections and touch on the causes of the latent unease in the field. As a proposition to facilitate understanding and communication, as well as transfer into educational contexts, we present an all-embracing approach to socialemotional intelligence, competences and skills. 


\subsection{Intelligence, competence and skills}

Although the concept of intelligence as "the aggregate or global capacity of the individual to act purposefully, to think rationally, and to deal effectively with his environment" Wechsler (1944, p. 7) is generally accepted, its division into fluid and crystallized intelligence (Cattell, 1971) causes delimitation problems with other concepts such as competence (Wilhelm and Nickolaus, 2013). Fluid intelligence refers to the ability to solve problems and reason in new unknown situations, independent of the previously acquired knowledge (Jaeggi et al., 2008). Research reveals that it appears to be "robust against influences of education and socialization, and it is commonly seen as having a strong hereditary component" (Jaeggi et al., 2008, p. 1; Gray and Thompson, 2004; Cattell, 1963; Baltes et al., 1999). Crystallized intelligence, on the other hand, relies on the use of learned knowledge and experience (Cattell, 1963).

In contrast to intelligence, there is no internationally valid definition of competences. To complicate things even further, similar wording (i.e. competency) is also present in the educational context. Le Deist and Winterton point out that "“competence' generally refers to the functional areas and 'competency' to behavioral areas but usage is inconsistent" (2005, p.1). For this paper, we use the definition from Weinert who takes a cognitive approach, since his expertise laid the groundwork for the understanding of competence within the OECD. He defines " "competence' as referring to combinations of those cognitive, motivational, moral, and social skills available to (or potentially learnable by) a person or a social group that underlie the successful mastery through appropriate understanding and actions of a range of demands, tasks, problems, and goals" (Weinert, 2001b, p. 2433). One can see that competence is very similar to crystallized intelligence in a specific domain (Wilhelm and Nickolaus, 2013). Neither is robust against influences of education and socialization. On the contrary, they mostly result from them. One could imagine that (crystallized) intelligence represents the development of abilities into competences (Sternberg, 2005). This would explain why acquiring certain competences can increase success in intelligence tests (Sternberg, 2005).

Finally, in the literature and in dictionaries, skills are defined as the abilities that enable an action to be performed. As discussed in Chapter 1.2, performance is included in some views of competence and, as previously mentioned, "the boundary between skill and competencies is fuzzy" (Weinert, 2001a, p.62).

\subsection{Action regulation modes of control}

In the educational context, performance through action is the scale on which statements regarding people's abilities are based. Since we are looking for structure in (educational) research approaches, it is important to combine the theoretical side with the applied or empirical one. According to Goleman (1995), emotional intelligence is a description of human dispositions or illustrations of personality with links to theories of action. To conduct the action-driven analysis, we use the action regulation theory by Hacker (2003). It describes three levels of modes of control. On the first level, action can take place in an automated, unconscious mode of regulation containing implicit automatisms and, if the situation allows, can be externalized through "prefabricated/motor programs" (p. 108). The second level is "knowledgebased" (p. 108), partly consciously controlled. It arises in cases in which situational cues are perceived and externalizes itself through pre-existing action schemes. Finally, the third level is the "strictly conscious intellectual mode" (p. 108) that arises 
when an intellectual analysis of the situation is necessary and action-based strategies must be found. One could conjecture that the three action regulation modes are linked to intelligence, competence and skills as shown in the following figure. The intellectual level, not based on any pre-existing schemes, would then only be deduced from fluid intelligence demanding new problem-solving aspects and pure reasoning without any dependencies on preexisting knowledge. The routine or automated level would only be derived from competences and skills since they are strictly automated and unconscious. And finally, the knowledge-based level would combine reasoning aspects of fluid intelligent nature with experiences, knowledge and skills in the meaning of crystallized intelligence. Figure 1 below shows these possible links. In a social situation, all three action regulation levels are likely to occur. In artificial situations, however, one could imagine that these are controllable, which would permit a new approach to measurement that could be considered in the future.

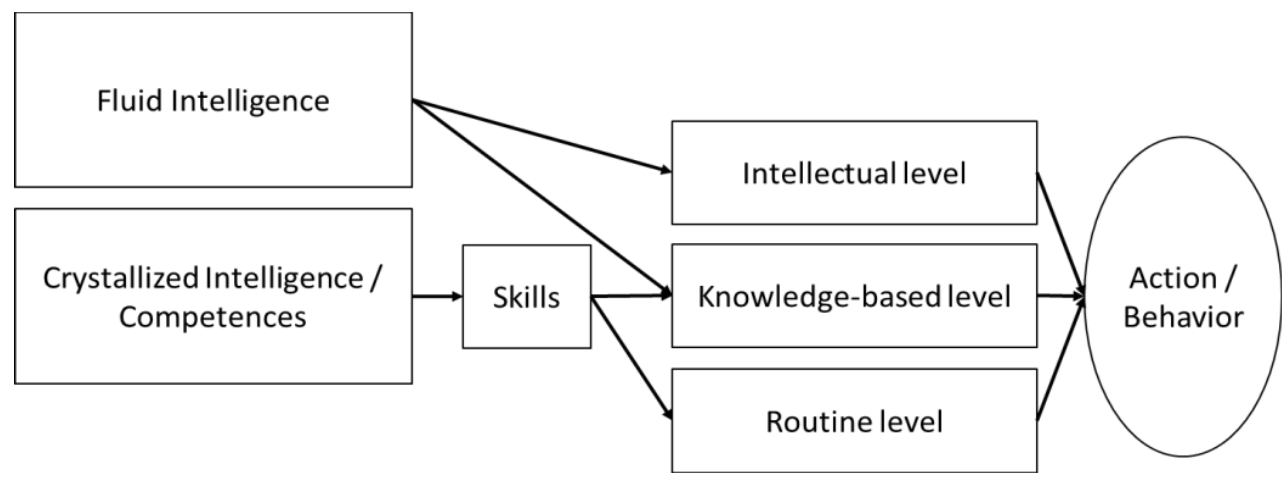

Figure 1: A possible link between intelligence, competence and skills with modes of action regulation

For the structure proposed by this paper, it would be important to combine the attributes presented in Chapter 2.6 (attributes that allow the awareness of one's inner state, attributes that allow the control/management of one's inner state, attributes that improve one's wellbeing, attributes that identify the state of others, attributes that allow the control/management of others' inner state and attributes that improve social interactions) with Hacker's action regulation levels presented above. Each of the attributes could be divided into the three levels. But in looking at the assessments above, one can see that the components of the tests are broken down in accordance with other rules, making it quasi impossible to "clean-up" the elements using this logic. Because of this, and still keeping it in mind for further analyzes and structuring exceeding the scope of this article, we concentrated on the presented six overall attributes and their division into intelligence, competence and skill elements in this paper.

\subsection{Social versus emotional?}

The final premise for the conceptual clean-up is the clarification of the difference between social and emotional. In looking at the definition of social intelligence, social competence and social skills, we see that emotions play a major role. But social components can be found in definitions of emotional competence as well (Saarni, 1990). As already mentioned, Bar-On (2006) emphasizes this point by using the term 
"emotional-social intelligence." Emotional components are found in almost every theory of social intelligence, social competence and social skills. In comparison to this, social aspects as "the knowledge of social matters" as defined by Vernon (1933, p. 40) almost never appear in emotional intelligence or emotional competence theories. For our approach, we first sought to differentiate these two components. After looking at the preexisting theories and measurement elements presented in Chapter 2 , however, we found that this was not possible. As previously described, emotional components are the main components of both social and emotional intelligence competence and skill theories and are therefore almost inseparable. Differentiation is only possible in social aspects, where we can find intelligence, competence and skill components related solely to knowledge and application of social rules, and therefore not of an emotional nature.

\subsection{Social-emotional intelligence, competences and skills structure}

In concluding this paper, we present a proposition for structuring social-emotional intelligence, competences and skills based on the information in Chapter 2. Due to space constraints, this has been done by way of example, allowing insight into what an extensive, all-embracing structure might look like. We used the six attributes presented in Chapter 2.6 (attributes that allow the awareness of one's inner state, attributes that allow the control/management of one's inner state, attributes that improve one's wellbeing, attributes that identify the state of others, attributes that allow the control/management of others' inner state and attributes that improve social interactions) to organize the elements of the above-presented validated assessments of social competence, emotional intelligence, emotional competence, social skills and social intelligence and to illustrate the proposed structure. Each one of the six attributes is presented in a table that can be found in the annexes. We then categorized each component of the presented measurements as either an intelligence, skill or competence element. This turned out to be very complicated, with some elements being allocated to more than one category. Difficulties in differentiating these components from personality traits and mood factors also arose.

Tables 1-6 in the annexes show how our theoretical analysis could be translated into a generalized structural model for social-emotional intelligence, competences and skills.

\section{Conclusion}

Personal and interpersonal intelligence, competences and skills are seen as important attributes and should be taught, supported and if possible assessed in educational pathways toward an occupation (KMK, 2007). Although research in this field has enormously grown in recent years, various problems have arisen. Firstly, theories of a different nature have many overlaps and secondly, there are major differences in definitions of supposedly identical concepts, resulting in confusion. These problems are primarily caused by the unclear nature and delimitations of intelligence, competence and skill concepts. Although there does seem to be awareness of these problems in the field, no effort has been made to structure the vast amount of information. On the contrary, even more individual "sub"-definitions are being created.

For educational purposes the difficulties this causes are enormous as there is no clear description of which intelligence component should be stimulated or which 
competence or skill dimension should be enhanced or taught, let alone assessed and evaluated.

Looking at preexisting and validated measurements of general social-emotional intelligence, competence and skills, we see that they are mostly based on selfevaluations. However, educational contexts need to reduce or eliminate subjectivity and to be as objective as possible, making self-evaluations less than ideal.

In this paper, we proposed a clean-up (Organ, 1997) and structuration of the entire field that could serve as an all-embracing reference, enabling research to become more consistent and facilitating identification of clear levels of intelligence, competences and skills. For this, we looked at social-emotional intelligence, competence and skill theories and measurements as an entire field instead of as independent theories. We looked at the similarities and differences between each of the components and deduced six main attributes: attributes that allow the awareness of one's inner state, attributes that allow the control/management of one's inner state, attributes that improve one's wellbeing, attributes that identify the state of others, attributes that allow the control/management of others' inner state and attributes that improve social interactions. We then tried to find an underlying structure, which led us to the action regulation theory and its link to the definitions of intelligence, competence and skills. Because of the extent of this paper, we chose to keep the subdivision of the six attributes into intelligence, competence and skills, not differentiating between action regulation levels and combined it with a possible differentiation between social and social-emotional elements. The result is presented in six exemplary tables in the annexes.

We think that this representation facilitates communication in research as well as transfer to the educational context. It allows identification of concrete entities that could be integrated into educational syllabi and adapted to post-educational demands.

In future research, two approaches should be combined in order to achieve the proposed structure. Firstly, a profound meta-analysis is needed to confirm, enlarge or reduce the proposed structure and fill up the categories with concrete and applicable examples. Secondly, an assemblage of social-emotional intelligence, competence and skill components, detached from preexisting measurements and structured by the six presented attributes and action regulation level, is also needed. Personality and mood should be examined in connection with the intelligence, competence and skill components as well to reduce additional confusion. 


\section{References}

Ananiadou, K. \& Claro, M. (2009). 21st century skills and competences for new millennium learners in OECD countries. Paris: Organization for Economic Cooperation and Development.

Arnold, K.-H.; Lindner-Müller, C. \& Riemann, R. (2012). Erfassung sozialer Kompetenz bei Kindern und Erwachsenen: Eine Expertise für das Nationale Bildungspanel für Deutschland (NEPS), NEPS Working Paper No.7.

Baltes. P. B.; Staudinger, U. M. \& Lindenberger, U. (1999). Lifespan psychology: Theory and application to intellectual functioning. Annual Revue of Psychology, 50, 471-507.

Bar-On, R. (1997a) (unpublished manuscript). The Emotional Quotient Inventory (EQ-i): a test of emotional intelligence. Toronto, Canada: Multi-Health Systems, Inc.

Bar-On, R. (1997b). The Emotional Quotient Inventory (EQ-i): technical manual Toronto, Canada: Multi-Health Systems, Inc.

Bar-On, R. (2006). The Bar-On model of emotional-social intelligence (ESI). Psicothema, 18, 13-25.

Baron R. \& Markman, G. (2003). Beyond social capital: The role of entrepreneurs' social competence in their financial success, Journal of Business Venturing, 18, 41-60.

Bayer, M.; Ditton, H. \& Wohlkinger, F. (2012). Konzeption und Messung sozialer Kompetenz im Nationalen Bildungspanel. NEPS Working Paper No.8.

Beelmann, A.; Pfingsten, U. \& Lösel, F. (1994). The effects of training of social competence in children: A meta-analysis of recent evaluation studies. Journal of Clinical Child Psychology, 23, 260-271.

Boyatzsis, R. E.; Goleman, D. \& Rhee, K. S. (2000). Clustering competence in emotional intelligence. In: R. Bar-On \& J. D. A. Parker (Eds.), The handbook of emotional intelligence (pp. 343-362). San Francisco: Jossey-Bass.

Boyatzis, R. E. \& Sala, F. (2004). The Emotional Competence Inventory (ECI). In: G. Geher (Ed.), Measuring emotional intelligence: Common ground and controversy (pp. 147-180). New York: Nova Science.

Cattell, R. B. (1963). Theory of fluid and crystallized intelligence: A critical experiment. Journal of Educational Psychology, 54, 1-22.

Cattell, R. B. (1971). Abilities: Their structure, growth, and action. New York: Houghton Mifflin.

Conte, J. M. (2005). A review and critique of emotional intelligence measures. Journal of Organizational Behavior, 26(4), 433-440.

Dede, C. (2007). Transforming Education for the 21st century: new pedagogies that help all students attain sophisticated learning outcomes.

Dietzen, A.; Monnier, M. \& Tschöpe, T. (2012) (unpublished manuscript). Soziale Kompetenzen von medizinischen Fachangestellten messen? : Entwicklung eines Verfahrens im Projekt CoSMed. BWP Qualifizierung in Gesundheits- und Pflegeberufen, 6/2012, 24-28.

Dietzen, A.; Monnier, M.; Srbeny, C.; Tschöpe, T. \& Kleinhans, J. (in press). Entwicklung eines berufsspezifischen Ansatzes zur Modellierung und Messung sozial-kommunikativer Kompetenzen bei Medizinischen Fachangestellten. In: R. Weiß for the Bundesisntitut für Berufsbildung (Ed.), Bildungsstandards und Kompetenzorientierung. Bonn. 
Döpfner, M.; Schlüter, S. \& Rey, E.-R. (1981). Evaluation eines sozialen Kompetenztrainings für selbstunsichere Kinder im Alter von neun bis zwölf Jahren: Ein Therapievergleich. Zeitschrift für Kinder- und Jugendpsychiatrie, 9, 233252.

Euler, D.; Bauer-Klebl, A. (2008). Bestimmung und Präzisierung von Sozialkompetenzen. Theoretische Fundierung und Anwendung für die Curriculumsentwicklung. ZBW, 104, 16-47.

Goleman, D. (1995). Emotional intelligence. New York: Bantam Books.

Goleman, D. (1998). Working with emotional intelligence. New York:Banta Books.

Gouley, K. K.; Brotman, L. M. \& Huang, K.-Y. (2008). Construct validation of the Social Competence Scale in preschool-age children. Social Development, 17(2), 380-398.

Gray, J. R.; Thompson, P. M. (2004). Neurobiology of intelligence: Science and ethics. National Revue of Neurosciences, 5, 471-482.

Gresham, F. M. \& Elliott, S. N. (2008). Social Skills improvement System- Rating Scales. Minneapolis, MN: Pearson Assessments.

Hacker, W. (2003). Action regulation theory: A practical tool for the design of modern work processes. European Journal of Work and Organizational Psychology, $12,105-130$.

Hartig, J. \& Klieme, E. (2006). Kompetenz und Kompetenzdiagnostik. In: K. Schweizer (Ed.), Leistung und Leistungsdiagnostik (pp. 127-143). Berlin: Springer.

Havighurst, L.C.; Fields, L. E. \& Fields, C. L. (2003). High versus low fidelity simulations: does the type of format affect candidates performance or perceptions. In: Proceedings from the 27th annual IPMAAC conference on personnel assessment, Baltimore.

Hunt, T. (1928). The measurement of social intelligence. Journal of Applied Psychology, 12, 317-334.

Jaeggi, S.M.; Buschkuel, M.; Jonides, J. \& Perrig, W.J. (2008). Improving fluid intelligence with training on working memory. Proceedings of the National Academy of Sciences of the United States of America, 105, 6829-6833.

Kanning, U. P. (2002). Soziale Kompetenz - Definition, Strukturen und Prozesse. Zeitschrift für Psychologie, 210, 154-163.

Kanning, U. P. (2003). Diagnostik sozialer Kompetenzen. Göttingen: Hogrefe.

Kanning, U. P. (2005). Soziale Kompetenzen. Entstehung, Diagnose und Förderung. Göttingen: Hogrefe.

Kanning, U. P. (2009). Inventar sozialer Kompetenzen (ISK). Manual. Göttingen: Hogrefe.

Klieme, E.; Maag Merki, K. \& Hartig, J. (2007). Kompetenzbegriff und Bedeutung von Kompetenzen im Bildungswesen. In: J. Hartig et al (Eds.), Möglichkeiten und Voraussetzungen technologiebasierter Kompetenzdiagnostik (pp.5-15). Berlin: BMBF.

KMK (2007). Handreichung für die Erarbeitung von Rahmenlehrplänen der Kultusministerkonferenz für den berufsbezogenen Unterricht in der Berufsschule und ihre Abstimmungen mit den Ausbildungsordnungen des Bundes für anerkannte Ausbildungsberufe. Bonn.

LaFreniere, P. J. \& Dumas, J. E. (1996). Social competence and behavior evaluation in children ages 3 to 6 years: The short form (SCBE-30). Psychological Assessment, 8(4), 369-377. 
LaFreniere, P.; Masataka, N.; Butovskaya, M.; Chen, Q.; Dessen, M. A. \& Atwanger, K. (2002). Cross-cultural analysis of social competence and behavior problems in pre-schoolers. Early Education \& Development, 13(2), 202-219.

Le Deist, F. D. \& Winterton, J. (2005). What is competence? Human Resource Development International, 8, 27-46.

Lerner, R. M. (2007). The Good Teen: Rescuing Adolescents from the Myths of the Storm and Stress Years. New York, NY: The Crown Publishing Group.

Matson, J. L.; Rotatori, A. F. \& Helsel, W. J. (1983). Development of a rating scale to measure social skills in children: The Matson Evaluation of Social Skills with Youngsters (MESSY). Behaviour Research and Therapy, 21(4), 335-340.

Mayer, J. D. \& Salovey, P. (1997). What is emotional intelligence? In P. Salovey \& D. Sluyter (Eds.), Emotional development and emotional intelligence: Educational implications (pp. 3-31). New York: Basic Books.

Mayer, J. D.; Caruso, D. R. \& Salovey, P. (1999). Emotional Intelligence meets traditional standards for an intelligence. Intelligence, 27, 267-298.

Mayer, J. D.; Salovey, P. \& Caruso, D. R. (2002a). Mayer-Salovey-Caruso Emotional Intelligence Test (MSCEIT). Toronto, Ontario: Multi-Health Systems, Inc.

Mayer, J. D.; Salovey, P. \& Caruso, D. R. (2002b). Mayer-Salovey-Caruso Emotional Intelligence Test (MSCEIT) user's manual. Toronto, Ontario, Canada: MHS Publishers.

Organ, D. W. (1997). Organizational citizenship behavior: It's construct clean-up time. Human Performance, 10, 85-97.

OECD (2001). Definition and Selection of Competencies: Theoretical and Conceptual Foundations (DeSeCo). Background Paper.

OECD (2013). Competency Framework. Brochure.

Rindermann, H. (2009). Emotionale-Kompetenz-Fragebogen. EKF ; Einschätzung emotionaler Kompetenzen und emotionaler Intelligenz aus Selbst - und Fremdsicht. Göttingen: Hogrefe.

Rose-Krasnor, L. (1997). The nature of social competence: A theoretical review. Social Development, 6, 111-135.

Saarni, C. (1990). Emotional competence: how emotions and relationships become integrated. In: R.A. Thompson (ed.): Socioemotional development. Nebraska symposium on motivation 36 (pp. 115-182). Lincoln, NE: University of Nebraska Press.

Salovey, P. \& Mayer, J. (1990). Emotional intelligence. Imagination, cognition, and personality, 9 (3), 185-211.

Scherer, K. R. (2001). Appraisal considered as a process of multi-level sequential checking. In K. R. Scherer, A. Schorr, \& T. Johnstone (Eds.), Appraisal processes in emotion: Theory, methods, research (pp. 92-120). New York: Oxford University Press.

Scherer, K. R. (2007). Componential emotion theory can inform models of emotional competence. In G. Matthews, M. Zeidner, \& R. D. Roberts (Eds.), The Science of Emotional Intelligence: Knowns and Unknowns. (pp. 101-126). Oxford: Oxford University Press.

Schuler, H.; Barthelme, D. (1995). In: B. Seyfried (Ed.): Stolperstein Sozialkompetenz: was macht es so schwierig sie zu erfassen, zu fördern und zu beurteilen? Bielefeld: Bertelsmann Verlag.

Schutte, N. S.; Malouff, J. M.; Hall, L. E.; Haggerty, D. J.; Cooper, J. T. \& Golden, C. J. (1998). Development and validation of a measure of emotional intelligence. Personality and Individual Differences, 25, 167-177. 
Seyfried, B. (1995). Stolperstein Sozialkompetenz: was macht es so schwierig sie zu erfassen, zu fördern und zu beurteilen? Bielefeld: Bertelsmann Verlag.

Silvera, D. H.; Martinussen, M. \& Dahl, T. I. (2001). The Tromsø Social Intelligence Scale, a self report measure of social intelligence. Scandinavian Journal of Psychology, 42, 313-319.

Steedly, K. M.; Schwartz, A.; Levin, M. \& Stephen, D. L. (2008). Social skills and academic achievement. Evidence for Education, 3(2), 1-8.

Sternberg, R. (2005). Intelligence, competence, and expertise. In: A. Elliot \& C. S. Dweck (Eds.), The handbook of competence and motivation (pp. 15-30). New York: Guilford Press.

Thorndike, E.L. (1920). Intelligence and its uses. Harper's Magazine, 140, 227-23.

Walker, H.M. (1983). The ACCESS program: Adolescent curriculum for communication and effective social skills: Student study guide. Austin, TX: Pro-Ed.

Warnes, E. D.; Sheridan, S. M.; Geske, J. \& Warnes, W. A. (2005). A contextual approach to the assessment of social skills: Identifying meaningful behaviors for social competence. Psychology in the Schools, 42, 173-187.

Waters, E. \& Sroufe, L. A. (1983). Social Competence as a developmental cosntruct. Developmental Review, 3, 79 -97.

Wechsler, D. (1944). The measurement of adult intelligence. Baltimore: Williams \& Wilkins.

Weinert, F.E. (2001a). Concept of Competence: A Conceptual Clarification. In: D.S. Rychen and L.H. Salganik (Eds.): Definition and Selection of Key Competencies (pp. 45-63). Seattle: Hogrefe \& Huber.

Weinert, F.E. (2001b). Competencies and Key Competencies: Educational Perspective. In: N. Smelser \& S. Baltes, (Eds.): International Encyclopedia of the Social and Behavioral Sciences (pp. 2433 - 2436). Vol 4. Amsterdam: Elsevier.

Weis, S. (2008). Theory and Measurement of Social Intelligence as a Cognitive Performance Construct. Doctoral dissertation. Otto-von-Guericke-University Magdeburg, Germany.

Wilhelm, O. \& Nickolaus, R. (2013). Was grenzt das Kompetenzkonzept von etablierten Kategorien wie Fähigkeit, Fertigkeit oder Intelligenz ab? In D. Leutner, E. Klieme, J. Fleischer \& H. Kuper (Eds.), Kompetenzmodelle zur Erfassung individueller Lernergebnisse und zur Bilanzierung von Bildungsprozessen: aktuelle Diskurse im DFG-Schwerpunktprogramm. 18. Sonderheft der Zeitschrift für Erziehungswissenschaft.

Winther, E. (2010). Kompetenzmessung in der beruflichen Bildung. Bielefeld.

Vernon, P.E. (1933). Some characteristics of the good judge of personality. Journal of Social Psychology, 4, 42-57.

Zins, J.; Weissbert, R.; Wang, M. \& Walberg, H. (2004). Building academic success on social and emotional learning: What does the research say? New York: Teachers College Press. 


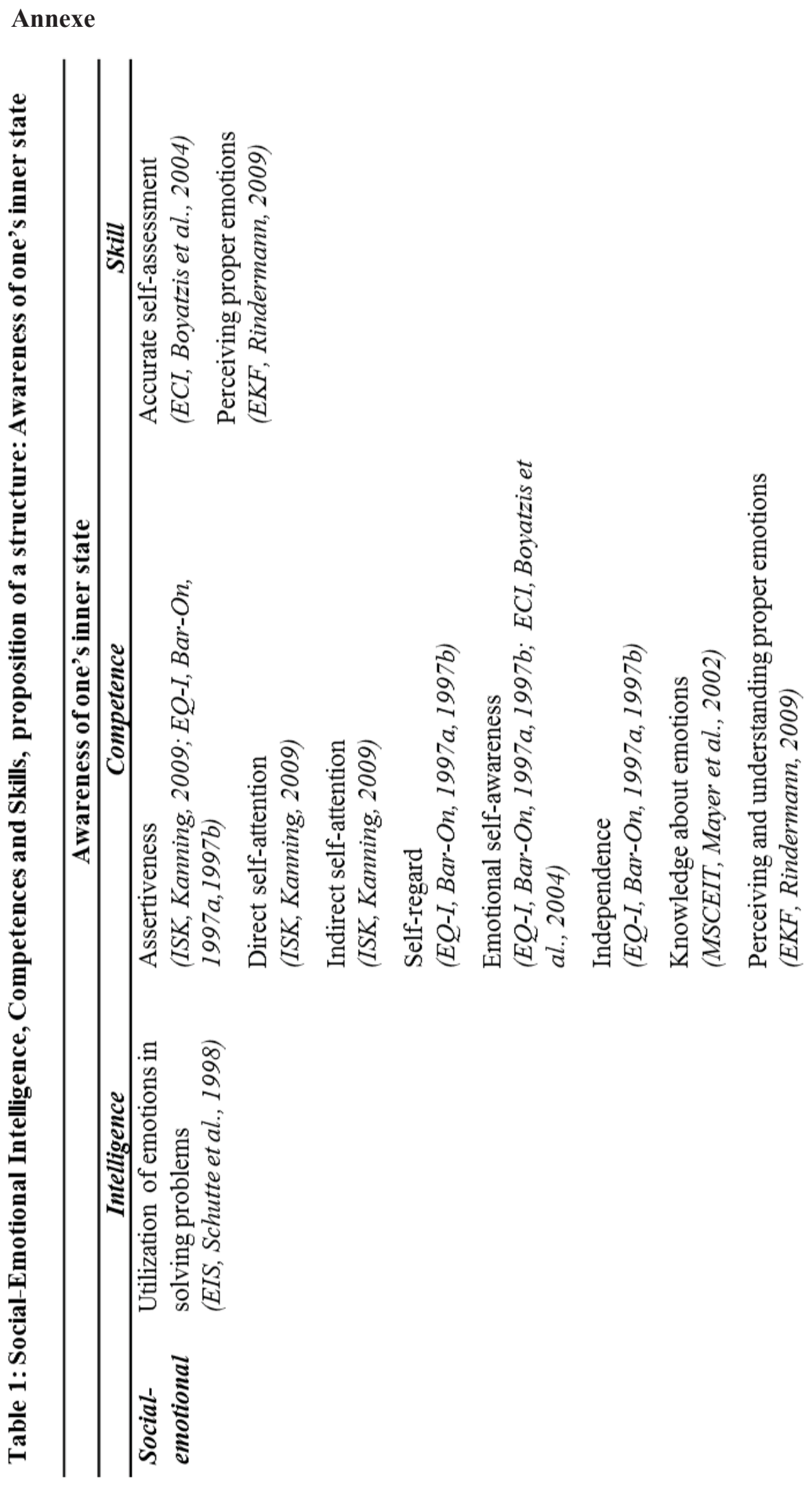




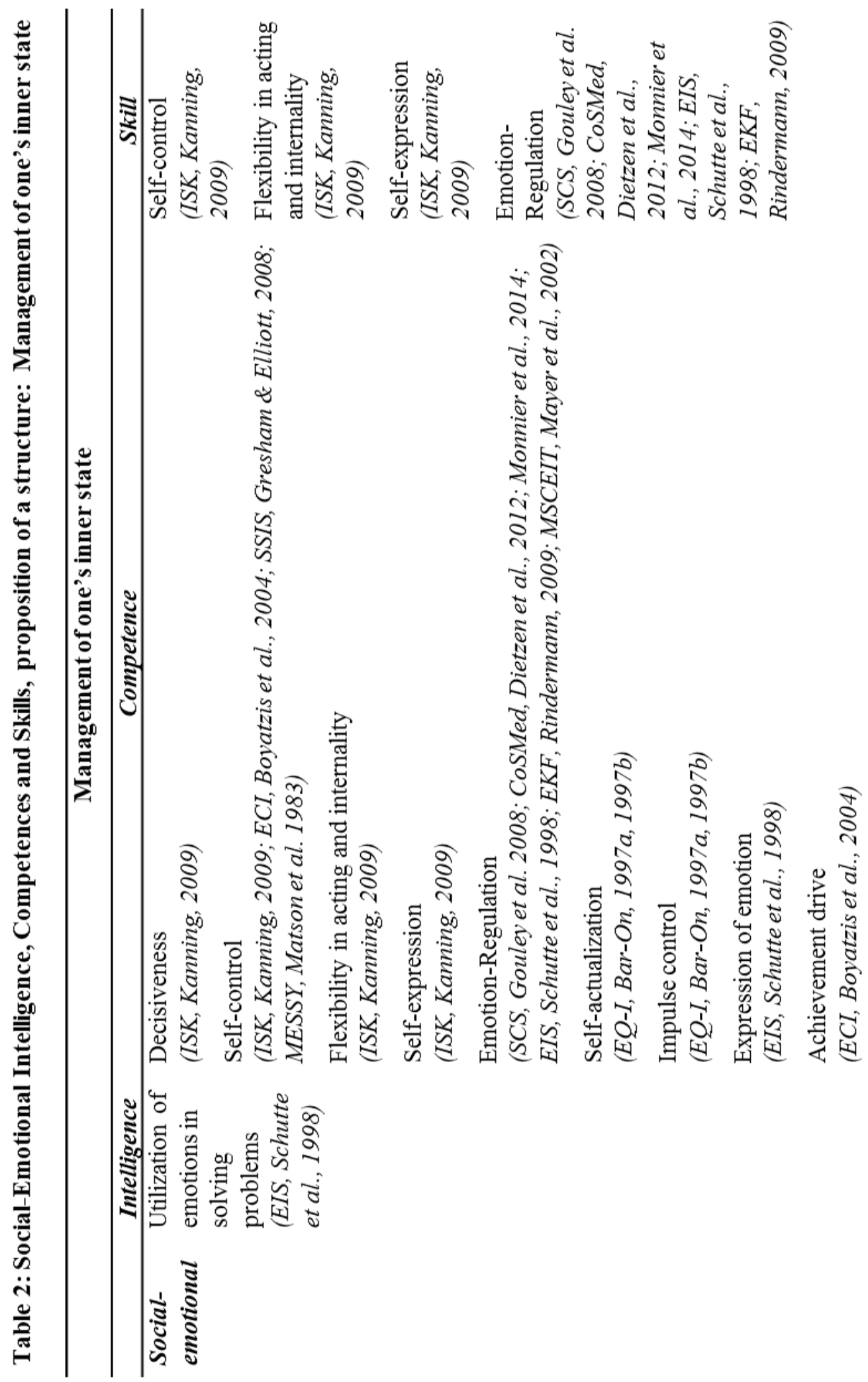




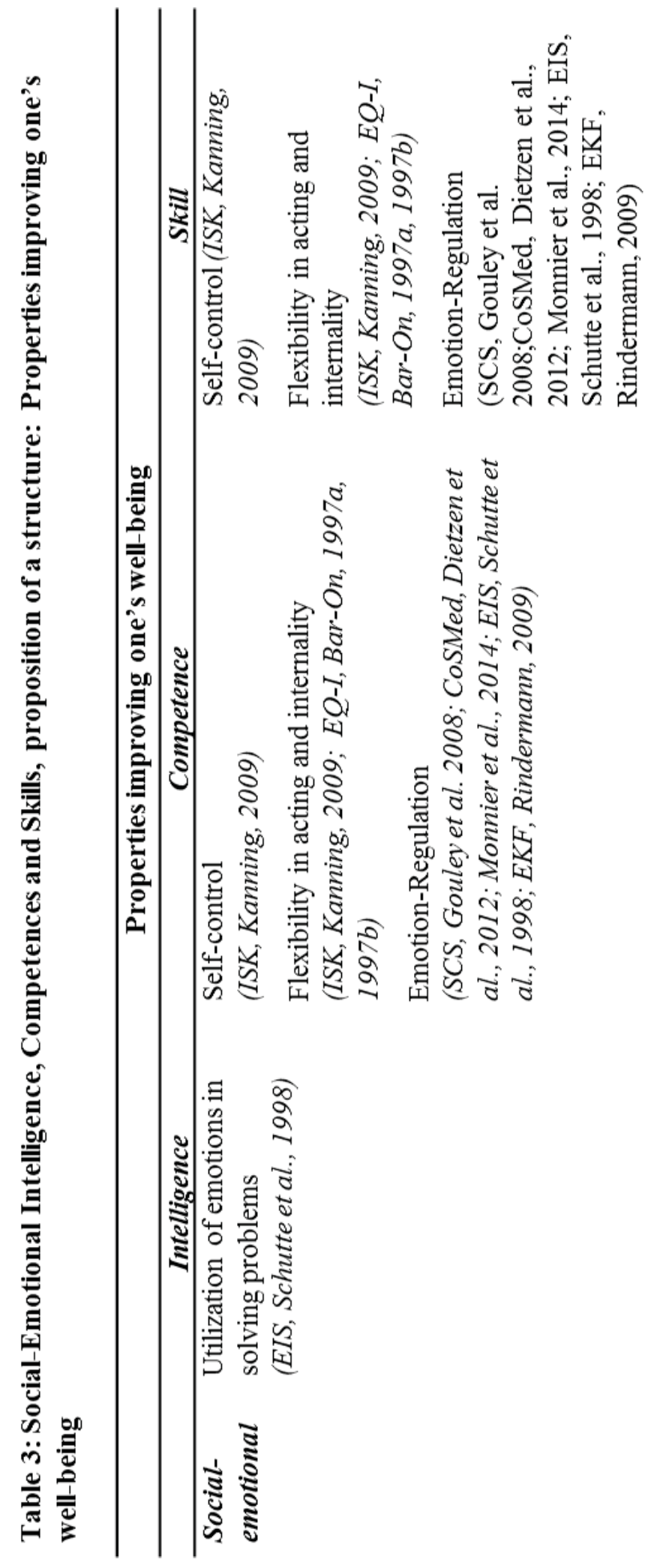




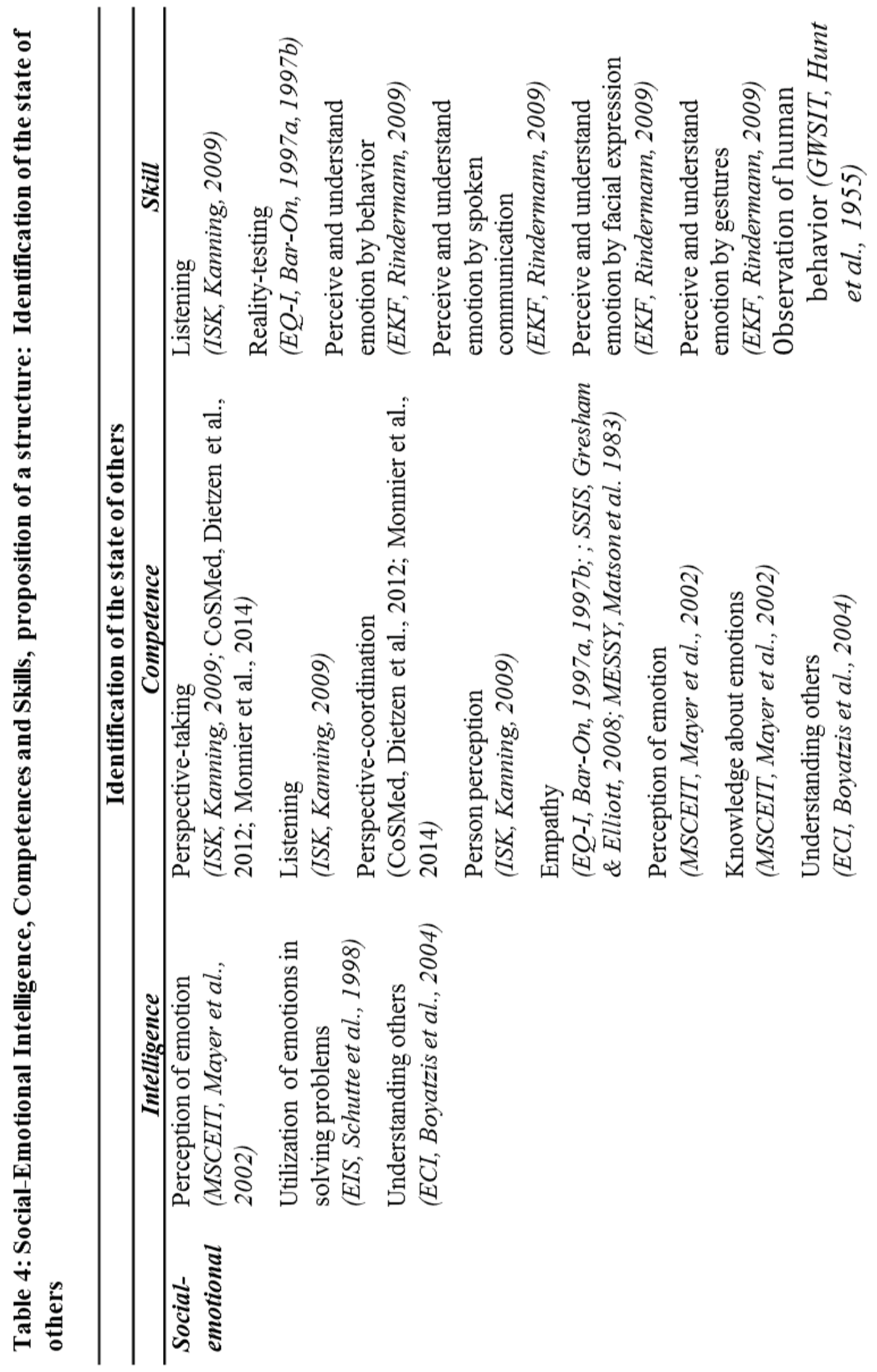




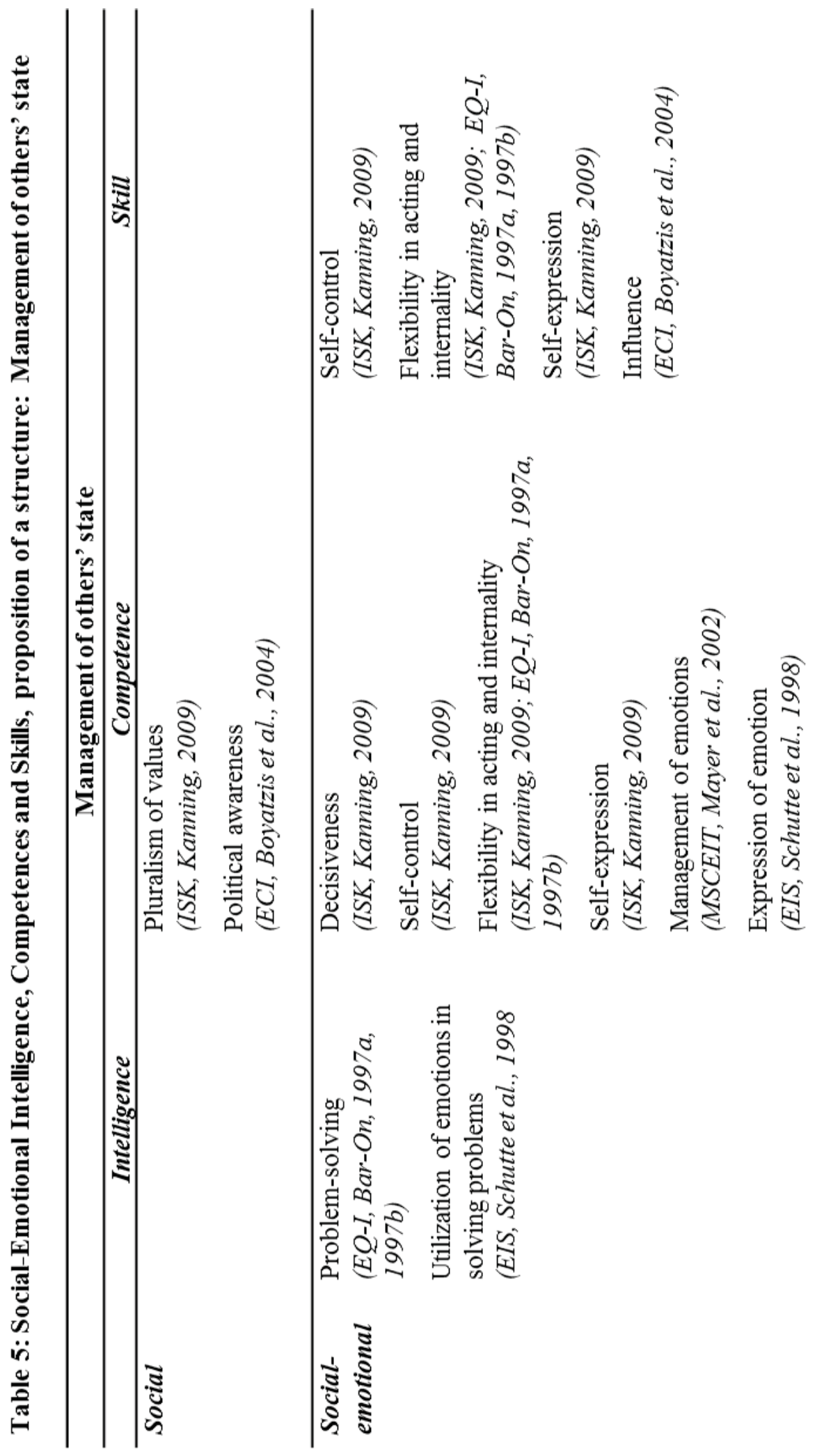




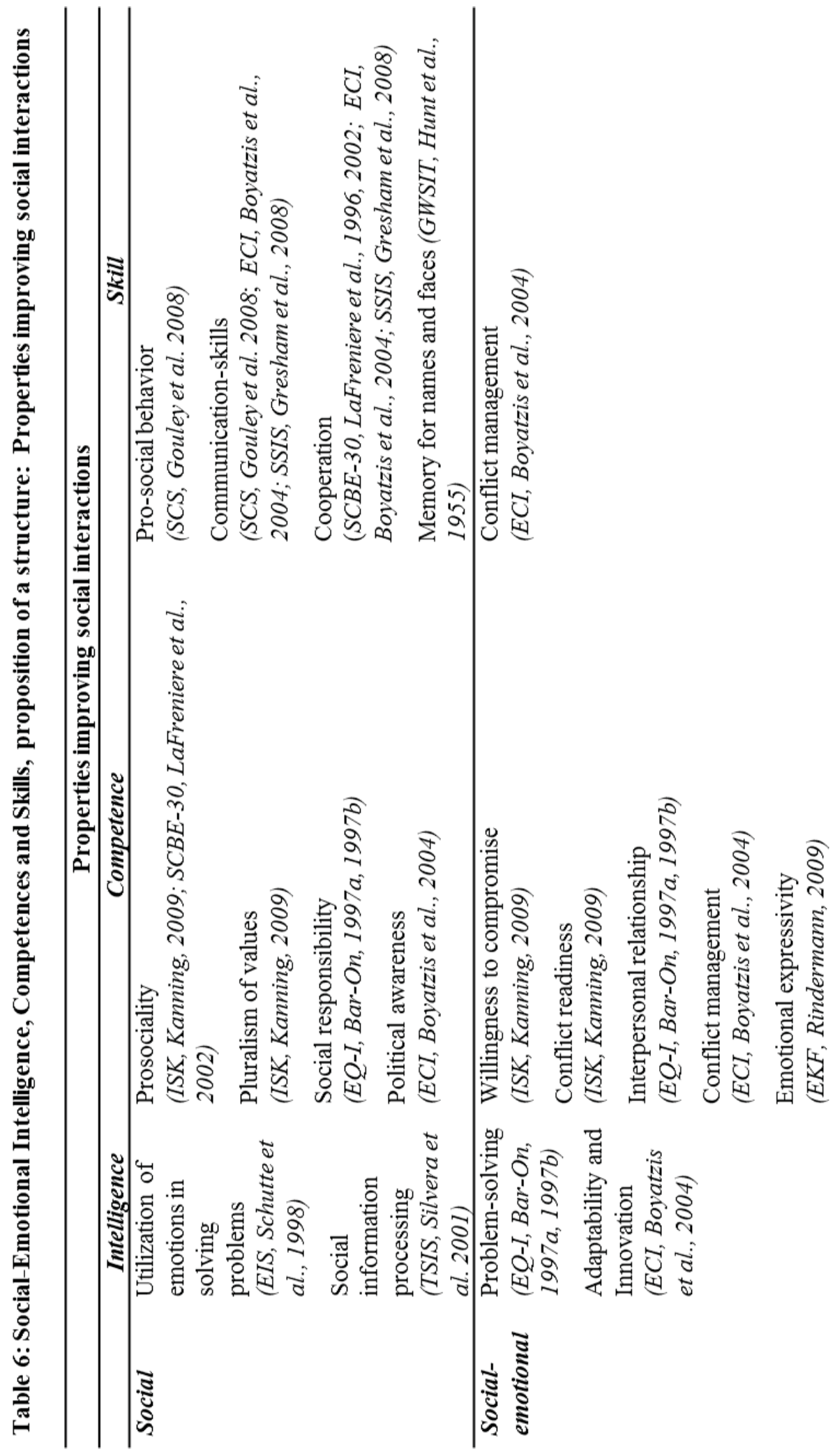

